\title{
MBTH: A novel approach to rapid, spectrophotometric quantitation of total algal carbohydrates
}

Stefanie Van Wychen, William Long, Stuart K. Black, and Lieve M.L. Laurens*

Keywords: algae, carbohydrates, spectrophotometric, phenol-sulfuric acid, MBTH 


\begin{abstract}
:
A high-throughput and robust application of the 3-methyl-2-benzothiazolinone hydrazone (MBTH) method was developed for carbohydrate determination in microalgae. The standard phenol-sulfuric acid method to quantify carbohydrates is strongly affected by algal biochemical components and exhibits a highly variable response to microalgal monosaccharides. We present a novel use of the MBTH method to accurately quantify carbohydrates in hydrolyzate after acid hydrolysis of algal biomass, without a need for neutralization. The MBTH method demonstrated consistent and sensitive quantitation of algae-specific monosaccharides down to $5 \mu \mathrm{g} \mathrm{mL}{ }^{-1}$ without interference from other algae acidic hydrolyzate components.
\end{abstract}


Determining which of the value-added pathways are economically advantageous for algae feedstocks necessitates the accurate quantitation of process relevant compounds such as lipids, proteins, and carbohydrates; with carbohydrates being one of the more challenging components to quantify reproducibly and accurately [1]. Quantitation of carbohydrates using a traditional phenol-sulfuric acid (PSA) method [2,3] as a one-step hydrolysis and colorimetric reaction for whole algal biomass is limited due to 1) over or under quantitation due to interference from pigments, lipids and proteins, 2) highly variable response from different monomeric sugars, and 3) insensitivity to some algae specific monosaccharides. Typical PSA procedures involve the addition of concentrated sulfuric acid and a dilute phenol solution directly to algal biomass, followed by incubation for $5 \mathrm{~min}$ at $90^{\circ} \mathrm{C}$ and measurement of the absorbance at $490 \mathrm{~nm}$. The reaction is based on the dehydration of carbohydrates and formation of furan derivatives, which produce an orange color complex in the presence of phenol. One limitation, beyond the toxicity of the products used is the variable response of different sugars. A pentose sugar like xylose will produce a spectrum with a bimodal peak (Fig. 1 A), which is not the case for hexose sugars such as glucose and thus calibrations based on glucose can not be transferred accurately to the quantification of pentose sugars (Fig. 1 B), as has been done in the past [3]. When performed directly on whole biomass, this method produces variable spectral responses based on the sugars present in the sample, which makes accurate quantitation of complex sugar samples challenging if not impossible. In addition, pigments, lipids, and proteins severely interfere with the method, likely because of side reactions with these compounds. Interference reaction mechanisms were suggested between amino compounds and sugars during the dehydration of sugars in the 
presence of high acid concentrations [4,5]. As an alternative, the MBTH reaction chemistry proceeds through the complexation of the aldehyde group of neutral monosaccharides with MBTH to form a blue color complex. The method was originally developed for aliphatic aldehydes [6], with a later published application for the detection and quantitation of monosaccharides [7]. The method involved the reaction of MBTH with monosaccharides under alkaline conditions at $80^{\circ} \mathrm{C}$, followed by the complexation of a second MBTH molecule with the addition of an acidic ferric solution and measurement of the absorbance at $620 \mathrm{~nm}$. The compatibility of this derivatization method with prior inorganic acid hydrolysis of whole algal biomass to release monosaccharides has not been studied and was the subject of the application and method development described here. Here we present our evaluation of the MBTH method for the quantitation of algae-specific monosaccharides directly in sulfuric acid hydrolyzates from algal biomass. Providing the basis for a rapid, accurate carbohydrate quantitation procedure for microalgae. The elimination of neutralization of the acid hydrolysis residue speeds up the analysis and this method lends itself well to micro-titer plate highthroughput adaptation.

To illustrate the variable spectral response of sugars using the PSA method, we evaluated the colorimetric responses of the furan-phenol complexes of several common algal sugars (Fig. 1 A-B). The spectrum for representative hexose (glucose), pentose (xylose) and deoxy-hexose (fucose) illustrate the different responses of algal sugars at $490 \mathrm{~nm}$. This observation supports the opinion that the PSA method is unable to accurately quantify the summation of the complex mixture of algae-specific monosaccharides. 
To develop and implement the MBTH method as an alternative to PSA, we first established the limits of detection using a reference glucose calibration curve. Monosaccharides were derivatized based on a previously described method [7]. In summary, $500 \mu \mathrm{L}$ of sample containing the appropriate amount of sugar was combined with $500 \mu \mathrm{L} 0.5 \mathrm{M} \mathrm{NaOH}$ and $500 \mu \mathrm{L}$ 1:1(v/v) DTT:MBTH (prepared fresh at the time of analysis from $1 \mathrm{mg} \mathrm{mL}^{-1} \mathrm{DTT}$ and $3 \mathrm{mg} \mathrm{mL}^{-1} \mathrm{MBTH}$ ). Samples were heated at $80^{\circ} \mathrm{C}$ for $15 \mathrm{~min}$ and then $1 \mathrm{~mL}$ of a $0.25 \mathrm{M} \mathrm{HCl}$ solution containing by wt. $0.5 \%$ ferric ammonium sulfate dodecahydrate and $0.5 \%$ sulfamic acid was added to each sample as they were removed from the hot block. After cooling, samples were diluted with $2.5 \mathrm{~mL}$ DI water and an absorbance reading was recorded at $620 \mathrm{~nm}$ for each sample. The lower limit of detection (LOD) was calculated as 4 times the standard deviation of the average reagent blank absorbance (defined as the noise in measurements). The upper limit of detection was determined by the linearity of the glucose calibration up to the maximum absorbance of 2 (1\% transmittance). The resulting calibration curve ranged from $4 \mu \mathrm{g} \mathrm{ml}^{-1}$ to $100 \mu \mathrm{g}$ $\mathrm{ml}^{-1}$ glucose. We then tested glucose at 60,80 , and $90^{\circ} \mathrm{C}$ for 5,15 , and $30 \mathrm{~min}$ to establish maximum color development, with the optimum parameters found to be $80^{\circ} \mathrm{C}$ for 15 min, consistent with previously published data [7]. A total of 11 algae-specific monosaccharides were analyzed by MBTH to determine spectral curves and response factors. Five-point calibration curves ranging from $0.01 \mathrm{mg} \mathrm{mL}^{-1}$ to $0.05 \mathrm{mg} \mathrm{mL}^{-1}$ were compared on an $\mathrm{mg}$ and $\mu \mathrm{mol}$ basis for each monosaccharide, based on the spectroscopic response and linear correlation of MBTH. To test the quantitation on mixtures of algaespecific monosaccharides, we designed and tested a randomized sugar experiment using a mix of 7 of the most common algal sugars [1]. Fig. 1 C-D shows spectra and response 
factors on a weight basis after derivatization with MBTH, including 3 hexoses (glucose, galactose and mannose), 3 pentoses (ribose, xylose and arabinose), 2 deoxy-sugars (fucose and rhamnose), 2 uronic acids (glucuronic and galacturonic), and 1 amino-sugar (glucosamine). Table 1 shows the theoretical total and measured concentration based on a glucose calibration curve. Recoveries were between 98 and 106\%, with an average recovery of $103 \%$, indicating that this method is capable of quantifying a microalgaespecific mixture of monosaccharides.

In order to test the applicability of this method on monosaccharides present in sulfuric acid hydrolyzates, we first quantified glucose in $4 \%$ sulfuric acid solution to determine if the presence of the acid produces any matrix interference, thereby affecting the accuracy and precision of the quantitation. We initially attempted quantitation after calcium carbonate $\left(\mathrm{CaCO}_{3}\right)$ neutralization (as this is typical prior to quantitation by HPLC [1]) and found that using $\mathrm{CaCO}_{3}$ to neutralize the excess sulfuric acid caused an underestimation of glucose content (when compared to HPLC data, data not shown). We found that using a total of $30 \mu \mathrm{L}$ or less of the $4 \%$ sulfuric acid hydrolyzate in the initial $500 \mu \mathrm{L}$ dilution gave a recovery of $100 \%$ of the glucose present (Table 1).

We tested for potential interferences from proteins, since amino acids and peptides are likely to be present in acid hydrolyzates. Pigments and lipids were not investigated. The assumption is that pigments are hydrolyzed and broken down into non-interfering compounds during the two-step sulfuric acid hydrolysis and the literature indicated no interference from lipids. Previous work showed no effect of protein on the linearity of the glucose calibration curve [7], however no information could be found on the effect of protein on the quantitation of the carbohydrates in a real-world hydrolyzate product. 
Given that the protein content in algae can exceed $40 \mathrm{wt} \%$ [8-10], we tested the recovery of a glucose standard with the addition of a model soluble protein $(2: 1 \mathrm{w} / \mathrm{w}$ and $1: 2 \mathrm{w} / \mathrm{w}$ bovine serum albumin (BSA):glucose, corresponding to $1 \mathrm{mg} \mathrm{mL}^{-1}$ glucose and $0.5 \mathrm{mg}$ $\mathrm{mL}^{-1}$ and $2 \mathrm{mg} \mathrm{mL}^{-1}$ BSA respectively). The recovery of glucose dropped to 88 and $93 \%$ of the theoretical amount added to the reaction for the 2:1 and 1:2 ratio of BSA:glucose respectively. When comparing the spectra, we noticed minimal interference in the 620 $\mathrm{nm}$ region but perhaps a small increase in absorbance at the $390-400 \mathrm{~nm}$ region, corresponding to the higher concentration of BSA. This indicates that protein may interfere with reaction development if present at a high concentration relative to the carbohydrate level in the test solution. In most of the applications on whole biomass hydrolyzates produced with sulfuric acid at relatively low concentrations (2-4 \% (w/v), high protein levels are not expected due to incomplete hydrolysis of the protein present and thus we believe that protein interference should not impact carbohydrate quantitation. Finally, the MBTH method was used to quantitate carbohydrates in the two-step sulfuric acid hydrolyzates of 6 lyophilized algal biomass samples, representing 3 different harvest points; early, mid, late (Scenedesmus acutus and Chlorella vulgaris, courtesy of Drs. McGowen and Dempster, ASU) [11,12]. Whole algal biomass was hydrolyzed using a two-stage sulfuric acid hydrolysis $\left(1 \mathrm{~h}\right.$ at $30^{\circ} \mathrm{C}$ in $72 \mathrm{wt} \%$ sulfuric acid, followed by $1 \mathrm{~h}$ at $121{ }^{\circ} \mathrm{C}$ in $4 \mathrm{wt} \%$ sulfuric acid in an autoclave), as described before $[1,11]$. Soluble carbohydrates were determined by both MBTH derivatization relative to a glucose calibration and simultaneous HPLC using a Shodex SP-0810 column with refractive index detection [1]. We compared the MBTH data to corresponding HPLC data and found a recovery of 100 to $112 \%$ (Table 1). The relatively small differences between the 
two numbers are likely due to a combination of uncertainty around the MBTH or the HPLC quantitation e.g. the presence of protein, co-elution of some sugars on the HPLC, and the quantitation of only 5 sugars on the HPLC as opposed to total carbohydrates for MBTH. However, for the application we envision, the wide adoption of this method to rapidly quantify the total carbohydrate content in algal biomass, the precision is better than other available rapid quantitation techniques. The results from the PSA method for the same 6 algae samples are provided for comparison in Table 1. Recoveries when compared to the corresponding HPLC values were highly variable across species and harvest time, between 84 and 106\% for C. vulgaris and between 40 and $65 \%$ for $S$. acutus were measured. These data support our conclusion that the interference effects are species and also growth condition, and thus biomass composition dependent. When detailed information, such as on monomeric carbohydrate profile is necessary, techniques such as HPLC or HPAEC can provide a more comprehensive picture of the specific carbohydrates present. The rapid spectrophotometric MBTH derivatization method described here has been used for carbohydrate characterization and is implemented as an alternative to HPLC-based quantification [13].

In conclusion, we developed a novel application for an existing spectrophotometric assay, based on selective functional group derivatization and demonstrated its applicability in quantifying algae-specific monosaccharides in acidic whole-biomass hydrolyzates with minimal interferences and avoiding the need for neutralization of the solution prior to quantification. This represents a significant step in increasing the throughput of accurate characterization of algal carbohydrates. 


\section{Aknowledgement}

This work was supported by the U.S. Department of Energy under Contract No. DEAC36-08-GO28308 with the National Renewable Energy Laboratory as part of the BioEnergy Technology Office (BETO). 


\section{References}

[1] D. Templeton, M. Quinn, S. Van Wychen, D. Hyman, L.M.L. Laurens, Separation and quantification of microalgal carbohydrates, J. Chromatogr. A. 1270 (2012) 225-234.

[2] M. Dubois, K.A. Gilles, J.K. Hamilton, P.A. Rebers, F. Smith, Colorimetric method for determination of sugars and related substance, Anal. Chem. 28 (1956) 350-356.

[3] T. Masuko, A. Minami, N. Iwasaki, T. Majima, S.I. Nishimura, Y.C. Lee, Carbohydrate analysis by a phenol-sulfuric acid method in microplate format, Anal. Biochem. 339 (2005) 69-72.

[4] M.L. Wolfrom, R.D. Schuetz, L.F. Cavalieri, Chemical Interactions of Amino Compounds and Sugars. IV. Signficance of Furan Derivatives in Color Formation, J. Am. Chem. Soc. 71 (1949) 3518.

[5] M.L. Wolfrom, R.D. Schuetz, L.F. Cavalieri, Chemical Interactions of Amino Compounds and SUgars. III. the conversion of D-Glucose to 5-(hydroxymethyl)-2furaldehyde, J. Am. Chem. Soc. 70 (1948) 514-517.

[6] E. Sawicki, T.R. Hauser, T.W. Stanley, W. Elbert, The 3-Methyl-2benzothiazolone Hydrazone test, Anal. Chem. 33 (1961) 93-96.

[7] G.E. Anthon, D.M. Barrett, Determination of reducing sugars with 3-methyl-2benzothiazolinonehydrazone., Anal. Biochem. 305 (2002) 287-9.

[8] L.M.L. Laurens, T.A. Dempster, H.D.T. Jones, E.J. Wolfrum, S. Van Wychen, J.S.P. McAllister, et al., Algal biomass constituent analysis: method uncertainties and investigation of the underlying measuring chemistries., Anal. Chem. 84 (2012) 1879-87.

[9] A.B. Walker, D.L. Berlinsky, Effects of Partial Replacement of Fish Meal Protein by Microalgae on Growth, Feed Intake, and Body Composition of Atlantic Cod, N. Am. J. Aquac. 73 (2011) 76-83.

[10] S.P. Slocombe, M. Ross, N. Thomas, S. McNeill, M.S. Stanley, A rapid and general method for measurement of protein in micro-algal biomass., Bioresour. Technol. 129 (2013) 51-7.

[11] L.M.L. Laurens, S. Van Wychen, J.P. McAllister, S. Arrowsmith, T. a Dempster, J. McGowen, et al., Strain, biochemistry, and cultivation-dependent measurement variability of algal biomass composition., Anal. Biochem. 452 (2014) 86-95.

[12] P.E. Zemke, M.R. Sommerfeld, Q. Hu, Assessment of key biological and engineering design parameters for production of Chlorella zofingiensis (Chlorophyceae) in outdoor photobioreactors., Appl. Microbiol. Biotechnol. 97 (2013) 5645-55.

[13] S. Van Wychen, L.M.L. Laurens, Determination of Total Carbohydrates in Algal Biomass - Laboratory Analytical Procedure ( LAP ) http://www.nrel.gov/docs/fy16osti/60957.pdf, Golden, CO, 2015. 


\section{Figures and Tables:}

Figure 1: Overview of spectrophotometric responses for the phenol-sulfuric acid and MBTH reactions. (A) PSA absorbance spectrum for a representative hexose (glucose), pentose (xylose), deoxy-hexose (fucose), (B) PSA responses for algae specific monosaccharides, (C) MBTH absorbance spectrum for the three sugars described in (A) as well as an amino sugar (glucosamine) and a uronic acid (glucuronic acid), (D) MBTH responses for algae specific monosaccharides.

A

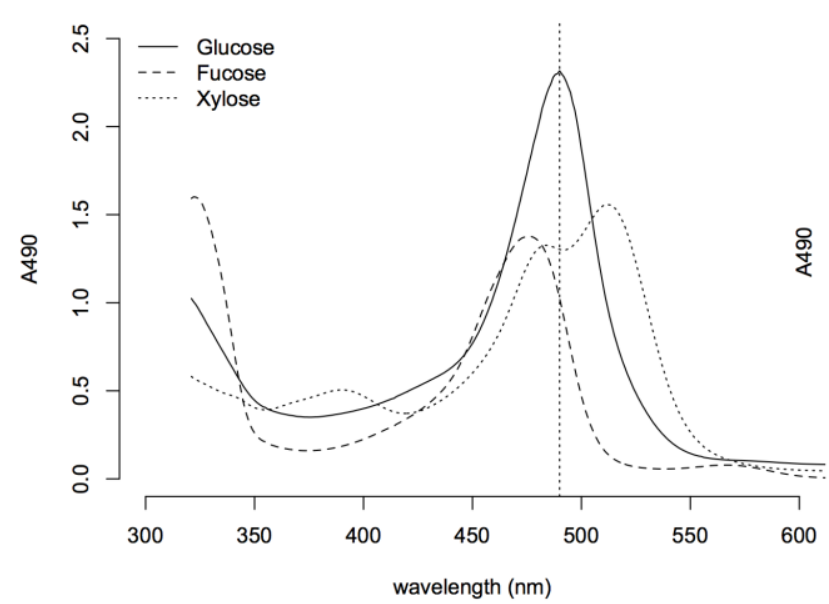

C

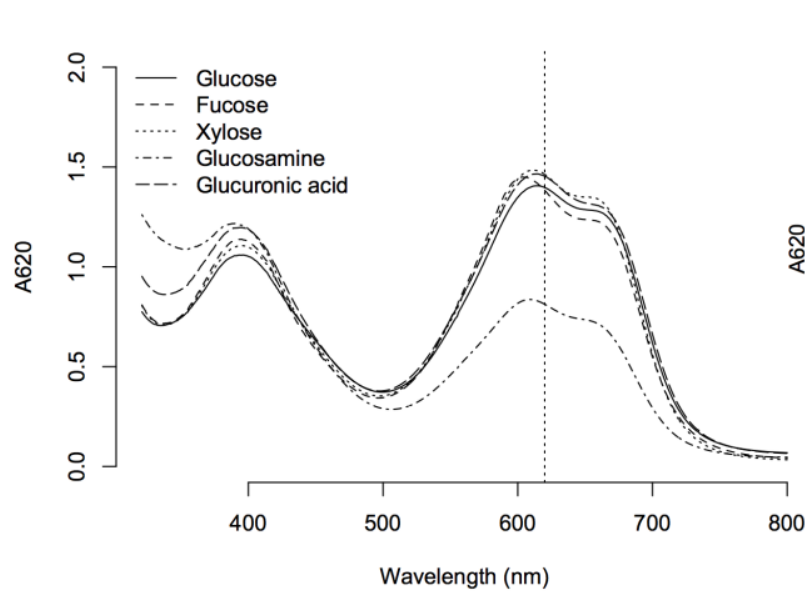

B

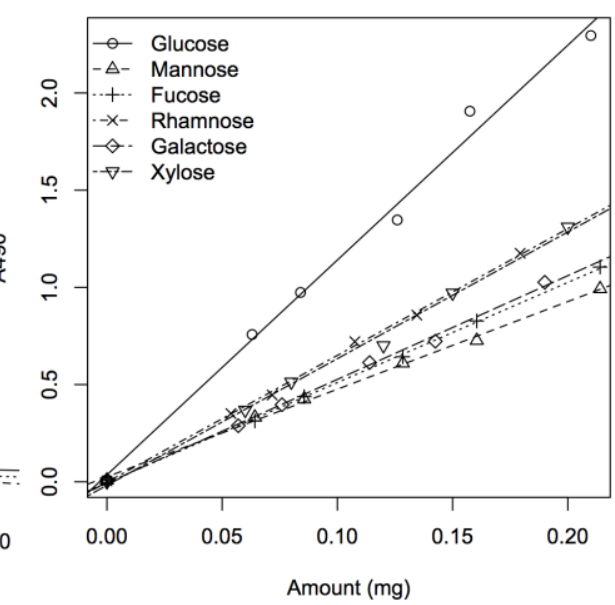

D

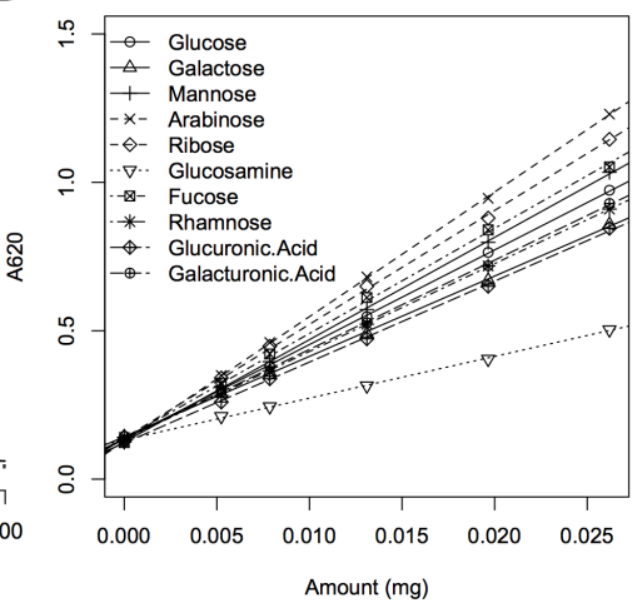


Table 1: Measured carbohydrate quantitation and recovery based on the MBTH reaction for various mixtures and matrices, alongside the quantitative recovery of whole biomass carbohydrates with phenol sulfuric acid

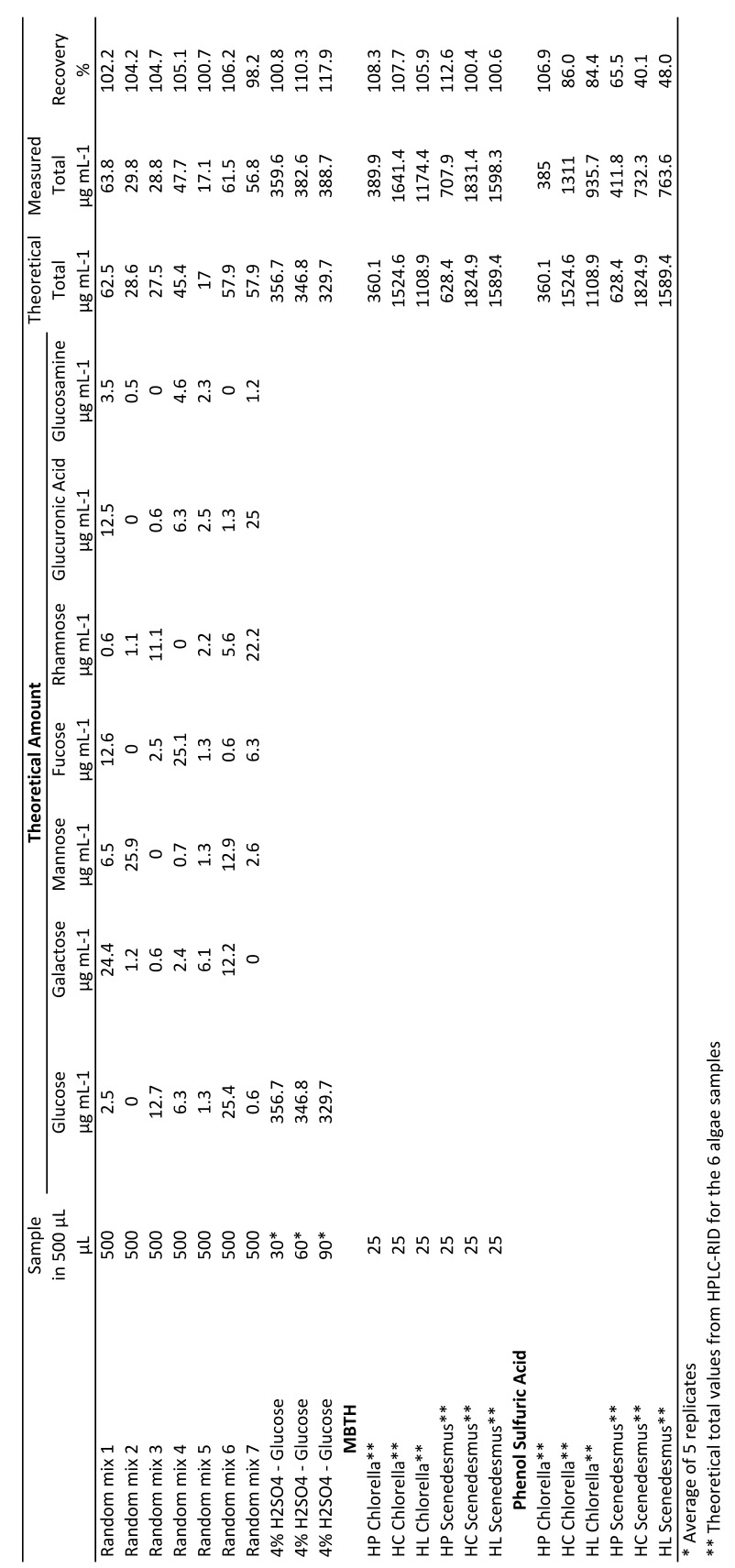


Tabl

$\begin{array}{ll}\text { Sample } & \text { Theoretical Amount }\end{array}$

Theoretical Measured

\begin{tabular}{|c|c|c|c|c|c|c|c|c|c|c|c|}
\hline & \multirow[b]{2}{*}{$\begin{array}{c}\text { in } 500 \mu \mathrm{L} \\
\mu \mathrm{L}\end{array}$} & & \multirow[b]{2}{*}{$\begin{array}{c}\text { Total } \\
\mu \mathrm{g} \mathrm{mL}-1\end{array}$} & \multirow[b]{2}{*}{$\begin{array}{c}\text { Total } \\
\mu \mathrm{g} \mathrm{mL-1}\end{array}$} & \multirow[b]{2}{*}{$\begin{array}{c}\text { Recovery } \\
\% \\
\end{array}$} \\
\hline & & $\begin{array}{l}\text { Glucose } \\
\mu \mathrm{g} \mathrm{mL-1} \\
\end{array}$ & $\begin{array}{c}\text { Galactose } \\
\mu \mathrm{g} \mathrm{mL}-1\end{array}$ & $\begin{array}{l}\text { Mannose } \\
\mu \mathrm{g} \mathrm{mL-1}\end{array}$ & $\begin{array}{c}\text { Fucose } \\
\mu \mathrm{g} \mathrm{mL}-1 \\
\end{array}$ & $\begin{array}{c}\text { Rhamnose } \\
\mu \mathrm{g} \mathrm{mL}-1\end{array}$ & $\begin{array}{l}\text { Glucuronic Acid } \\
\mu \mathrm{g} \mathrm{mL}-1\end{array}$ & $\begin{array}{c}\text { Glucosamine } \\
\mu \mathrm{g} \mathrm{mL}-1\end{array}$ & & & \\
\hline Random mix 1 & 500 & 2.5 & 24.4 & 6.5 & 12.6 & 0.6 & 12.5 & 3.5 & 62.5 & 63.8 & 102.2 \\
\hline Random mix 2 & 500 & 0 & 1.2 & 25.9 & 0 & 1.1 & 0 & 0.5 & 28.6 & 29.8 & 104.2 \\
\hline Random mix 3 & 500 & 12.7 & 0.6 & 0 & 2.5 & 11.1 & 0.6 & 0 & 27.5 & 28.8 & 104.7 \\
\hline Random mix 4 & 500 & 6.3 & 2.4 & 0.7 & 25.1 & 0 & 6.3 & 4.6 & 45.4 & 47.7 & 105.1 \\
\hline Random mix 5 & 500 & 1.3 & 6.1 & 1.3 & 1.3 & 2.2 & 2.5 & 2.3 & 17 & 17.1 & 100.7 \\
\hline Random mix 6 & 500 & 25.4 & 12.2 & 12.9 & 0.6 & 5.6 & 1.3 & 0 & 57.9 & 61.5 & 106.2 \\
\hline Random mix 7 & 500 & 0.6 & 0 & 2.6 & 6.3 & 22.2 & 25 & 1.2 & 57.9 & 56.8 & 98.2 \\
\hline 4\% H2SO4 - Glucose & $30 *$ & 356.7 & & & & & & & 356.7 & 359.6 & 100.8 \\
\hline 4\% H2SO4 - Glucose & $60^{*}$ & 346.8 & & & & & & & 346.8 & 382.6 & 110.3 \\
\hline 4\% H2SO4 - Glucose & $90^{*}$ & 329.7 & & & & & & & 329.7 & 388.7 & 117.9 \\
\hline \multicolumn{12}{|l|}{ MBTH } \\
\hline HP Chlorella** & 25 & & & & & & & & 360.1 & 389.9 & 108.3 \\
\hline HC Chlorella** & 25 & & & & & & & & 1524.6 & 1641.4 & 107.7 \\
\hline HL Chlorella** & 25 & & & & & & & & 1108.9 & 1174.4 & 105.9 \\
\hline HP Scenedesmus** & 25 & & & & & & & & 628.4 & 707.9 & 112.6 \\
\hline HC Scenedesmus** & 25 & & & & & & & & 1824.9 & 1831.4 & 100.4 \\
\hline HL Scenedesmus** & 25 & & & & & & & & 1589.4 & 1598.3 & 100.6 \\
\hline \multicolumn{12}{|c|}{ Phenol Sulfuric Acid } \\
\hline HP Chlorella** & & & & & & & & & 360.1 & 385 & 106.9 \\
\hline HC Chlorella** & & & & & & & & & 1524.6 & 1311 & 86.0 \\
\hline HL Chlorella** & & & & & & & & & 1108.9 & 935.7 & 84.4 \\
\hline HP Scenedesmus** & & & & & & & & & 628.4 & 411.8 & 65.5 \\
\hline HC Scenedesmus** & & & & & & & & & 1824.9 & 732.3 & 40.1 \\
\hline HL Scenedesmus** & & & & & & & & & 1589.4 & 763.6 & 48.0 \\
\hline
\end{tabular}

* Average of 5 replicates

** Theoretical total values from HPLC-RID for the 6 algae samples 